\title{
Gestão de Riscos e Desastres Naturais no Turismo: um estudo do município de Blumenau/SC
}

\section{Risk Management and Natural Disasters in Tourism: a study of the city of Blumenau/SC}

Fabricia Durieux Zucco ${ }^{1}$

Maria dos Remédios Antunes Magalhães ${ }^{2}$

Sérgio Luiz do Amaral Moretti ${ }^{3}$

\section{Resumo}

O objetivo deste estudo foi analisar a adequação das medidas de recuperação pós-desastre em um destino turístico. Com frequência crescente em todo o mundo, catástrofes naturais revelam questionamentos sobre os processos de gestão de riscos e de desastres. Realizada na cidade de Blumenau (SC), após a inundação de novembro de 2008, esta investigação norteou-se pelo modelo de resposta à crise proposto por Dwyer (2005) para analisar as medidas tomadas pela administração da cidade. Os resultados apontaram proximidade entre as estratégias de reabilitação adotadas e as prescrições do modelo e uma eficiente gestão da crise e dos riscos a ela associados. O estudo também pôde constatar que o histórico de Blumenau no enfrentamento de problemas semelhantes no passado e o aprendizado com o esforço coletivo de reconstrução foram elementos marcantes na superação da crise.

Palavras-chave: Blumenau; desastres naturais; recuperação; gestão de crise; turismo.

\begin{abstract}
The purpose of this study was to analyze the adequacy of the post-disaster into a tourist destination. With increasing frequency throughout the world, natural disasters reveal questions about the processes of risk management and disaster. Held in the city of Blumenau (SC), after the flood of November 2008, this research was guided by the model of response to crisis proposed by Dwyer (2005) to assess the measures taken by the city administration. The

\footnotetext{
${ }^{1}$ Doutoranda em Administração pela Universidade Nove de Julho (UNINOVE). Mestre em Administração pela Universidade Regional de Blumenau (FURB). Especialista em Gerenciamento de Marketing (FURB-INPG). Graduada em Comunicação Social - Habilitação em Publicidade e Propaganda (FURB). Professora da FURB e da Universidade do Vale do Itajaí (UNIVALI). Email: fabricia@furb.br.

2 Doutoranda em Marketing pela Universidade Nove de Julho (UNINOVE). Mestre em Administração Habilitação em Marketing pela UFPB. Graduada em Administração (UFPB). Professora da Universidade Federal de Campina Grande (UFCG). Email: remediosantunes@hotmail.com.

${ }^{3}$ Doutor em Ciências Sociais. Mestre e Bacharel em Administração pela Pontifícia Universidade Católica de São Paulo (PUC-SP). Professor do Programa de Mestrado e Doutorado em Administração - PMDA da Universidade Nove de Julho (UNINOVE). Email: moretti@uninove.br.
} 
results indicated the proximity of the rehabilitation strategies adopted with the requirements of the model and an efficient crisis management and the associated risks. The study also revealed that the history of Blumenau in facing similar problems in the past and learning from the collective efforts of reconstruction have been marked elements in overcoming the crisis.

Keywords: Blumenau; natural disasters; salvage; crisis management; tourism.

\section{Introdução}

Localizada no nordeste de Santa Catarina, a 21 metros acima do nível do mar, Blumenau é o centro da região metropolitana do Vale do Itajaí (formada por 16 municípios). Em seu território, de 519, 8 quilômetros quadrados, reside uma população de 301 mil habitantes.

As chuvas de novembro de 2008 em Santa Catarina demonstraram, mais uma vez, e de forma surpreendente, a vulnerabilidade da população a eventos extremos (DIAS; MINUZZI; 2009, p. 7). Os autores comentam que catástrofes como essa motivam uma série de perguntas sobre

a infraestrutura das cidades, vias de transporte, segurança pública em situações de emergência, além do fenômeno que causou a tragédia.

É preciso reconhecer que a maioria das crises provocadas por desastres naturais afetam não apenas as atividades diretamente associadas ao turismo, mas toda a cadeia de produção e oferta de bens e serviços. A crise evidenciou o grau de inter-relação da indústria do turismo com outros setores e revelou sua dependência do funcionamento da infraestrutura pública.

Embora cada caso tenha sua especificidade, as lições que outras regiões podem oferecer pela superação de desastres anteriores tornam-se importante guia nessas ocasiões. Dwyer (2005) mostrou que das grandes crises emergem certos padrões que podem fornecer lições vitais para orientar processos de gestão de riscos e de desastres. Ele resume sua argumentação em lições pautadas em dois grandes desastres: o tsunami que atingiu a Ásia em dezembro de 2004 e o furacão Katrina que devastou Nova Orleans em agosto de 2005.

O objetivo deste estudo foi analisar a adequação das medidas de recuperação pós-desastre em um destino turístico utilizando o modelo de resposta à crise, defendido por Dwyer (2005). A metodologia utilizada foi um estudo de caso que buscou verificar a compatibilidade entre as 
ações desenvolvidas na cidade de Blumenau a partir do desastre de novembro de 2008, e o modelo de resposta à crise proposto por Dwyer (2005). A estratégia de coletas de dados iniciou com uma pesquisa exploratória em publicações de relatos sobre a crise, seguida de entrevistas em profundidade com autoridades da administração municipal. Este trabalho apresenta a seguinte estrutura de tópicos: a revisão da literatura concernente a destinos turísticos e gestão de riscos e desastres, logo após segue-se a metodologia da pesquisa utilizada no estudo e uma exposição das consequências da crise e das medidas tomadas para reverter a situação. Por fim, comparam-se as estratégias e ações adotadas com as recomendações de Dwyer (2005).

\section{A Importância do Turismo e a Atratividade do Destino}

O turismo impacta positivamente na qualidade de vida das comunidades que o promovem, na medida em que o desenvolvimento econômico por ele provocado pode reduzir as disparidades sociais a partir do crescimento da oferta de empregos e melhor distribuição de renda. Essa atividade econômica dentro do setor de serviços representa uma inter-relação que depende da cultura e dos atrativos de uma região e é, de fato, uma prática social com base cultural e histórica, a um meio ambiente diverso, cartografia natural, relações sociais de hospitalidade e trocas de informações culturais (MOESCH, 2000, p. 09).

No entanto, o fortalecimento dessa capacidade depende, na visão de Acselrad (2002), da articulação entre poder público, iniciativa privada e sociedade civil, um movimento sinérgico das múltiplas escalas do poder local. É fundamental uma gestão capaz de potencializar a soma de fenômenos e relações originados da interação de turistas, empresas, governos locais e comunidades anfitriãs, no processo de atrair e receber turistas e outros visitantes (GOELDNER et al., 2002, p. 23). Como impacto positivo da atividade, os autores dão ênfase à construção de infraestrutura e de empreendimentos turísticos, ressaltando que tais obras fazem com que o dinheiro trazido pelos turistas circule por toda a sociedade.

Lickorish e Jenkins (2000) observam que o efeito multiplicador de renda traz uma interdependência entre os vários fatores econômicos, gera empregos em diversas áreas nos setores formais e informais e cria novas oportunidades para a população local. Sobre essa 
questão, Swarbrooke (2000) afirma que o turismo se tornou o principal motor da economia, incentivando o desenvolvimento de outras atividades econômicas, notadamente as indústrias de construção civil, hotelaria e transportes.

Nesse contexto, a atuação do governo local em promover o desenvolvimento significa intervir sobre as condições do ambiente social ou econômico, articulando medidas que propiciem o desenvolvimento do município. Mais do que agente realizador, a prefeitura deve funcionar como articuladora e facilitadora das ações que, segundo Dowbor (1995), têm eficácia maior quando o poder público é apenas um dos agentes envolvidos no projeto de desenvolvimento local incorporado pela sociedade.

$\mathrm{Na}$ análise de Krippendorf (2000, p. 47), harmonizar o desenvolvimento turístico implica, antes de tudo, desembaraçar o nó dos interesses, muitas vezes contraditórios, e estabelecer uma ordem de prioridades. Interessa destacar que o turismo como fator de desenvolvimento de uma cidade ou região comporta basicamente duas interfaces: a ação dos órgãos públicos e privados para melhorar a infraestrutura e a participação da comunidade no planejamento turístico, esta apontada por Irving (2002) como elemento essencial para a sustentabilidade desse processo.

O conceito-chave para Dowbor (1998, p. 66) é a articulação dos três elementos do triângulo, num movimento sinérgico, já que somos condenados a articular de maneira razoavelmente equilibrada os poderes do Estado, das empresas privadas e das organizações da sociedade civil. A esse respeito, Cooper (2001) considera que a melhoria na qualidade de vida da região é outro efeito econômico positivo, pois, a partir do momento em que a atividade turística surge na localidade, ela contribui para o equilíbrio do crescimento regional, ajudando assim a melhorar sua economia. Mas, não se pode esquecer que ela é sensível a variação na renda dos consumidores, oscilação dos preços praticados pelo mercado e efeitos climáticos negativos.

Cabe ressaltar que a atratividade é elemento fundamental para a inserção de um local no contexto do turismo, pois o interesse em conhecer determinada região se constitui como principal motivador do deslocamento de pessoas. A capacidade de atração se vincula a características naturais e culturais peculiares e, segundo Wilde e Cox (2008) é fortemente influenciada por fatores como preços diferenciados, produtividade e qualidade de vários 
componentes da indústria turística. Os autores identificam a cultura e o patrimônio como variáveis que têm potencial de afetar a posição competitiva de um destino.

Turismo pode funcionar como motivador da manutenção da identidade local, da herança cultural e do orgulho étnico, além de possibilitar a manutenção do patrimônio artístico e histórico (SIMÃO, 2001, p. 57). Especificamente sobre patrimônio cultural, Pellegrini Filho (2000, p. 92) salienta que ele não se restringe à arquitetura, a despeito da indiscutível presença das edificações como um ponto alto da realização humana e que o seu significado é muito amplo, incluindo outros produtos do sentir, do pensar, do agir humanos.

Importa ainda observar, com base nos argumentos de Choay (2001), que os símbolos materiais da cultura de um povo, como os monumentos e o patrimônio histórico, constituem produtos culturais distribuídos para consumo. Por esse prisma, os atrativos paisagísticos e patrimoniais do lugar se tornam recursos turísticos na medida em que são disponibilizados para uso e compartilhados com os visitantes. Interessante acréscimo a essa discussão é oferecido por Vaz (2001) ao sublinhar que o produto turístico comporta um conjunto de benefícios que o consumidor busca em uma determinada localidade e que envolvem um complexo de serviços oferecidos por diversas organizações. Aos atrativos naturais e culturais devem então estar associados os meios que possibilitam usufruir dessa oferta.

\section{Blumenau, a Cidade Inundada}

Ao chegar à região em 2 de setembro de 1850, um grupo de 17 alemães, liderado pelo farmacêutico Hermann Bruno Otto Blumenau, pretendia formar uma colônia agrícola, mas com o tempo a vocação industrial prevaleceu. Os produtos de qualidade fabricados pelos habitantes da cidade logo atraíram muitos visitantes que vinham fazer negócios ou comprar seus produtos. O movimento aumentou e a cidade de Blumenau se expandiu.

A cidade preserva os traços e a cultura dos colonizadores alemães, expressa no trabalho, na vida social, na arquitetura, nas artes e gastronomia. Nesse território apelidado de "Alemanha tropical", os visitantes podem percorrer quatro roteiros turísticos. O primeiro contempla a história e a cultura estampada em 41 atrativos turísticos no percurso pontes, praças, monumentos, arquitetura enxaimel, museus, igrejas e parque horto-botânico. O segundo reúne 


\section{TURISMO EM ANÁLISE}

museus, parques ecológicos e trilhas, locais onde o famoso cientista e naturalista Fritz Müller, amigo de Charles Darwin viveu e estudou a fauna e a flora do município, que proporciona também contato com a natureza e a prática de várias atividades de lazer, como caminhadas e observação de paisagens.

O terceiro roteiro oferece a oportunidade de, por meio de visitas a companhias têxteis e fabricantes de cristais, conhecer a força industrial da cidade. O último e ponto alto dos roteiros turísticos da cidade são as visitas às cervejarias artesanais, marca do povo alemão e importante setor econômico do município. O turista pode assistir ao processo de fabricação e provar os produtos, além de apreciar os belos cenários dos quais elas fazem parte.

Todo esse patrimônio blumenauense é, entretanto, vulnerável a fenômenos naturais agressivos, como chuvas torrenciais que provocam inundações no rio Itajaí-Açu (ver mapa 01) que corta a cidade, cujo histórico para esse tipo de desastre era bem evidente.

Mapa 01 - Mapa da Cidade de Blumenau: Rio Itajaí-açu corta o centro da cidade. Áreas de risco pós-tragédia de 2008

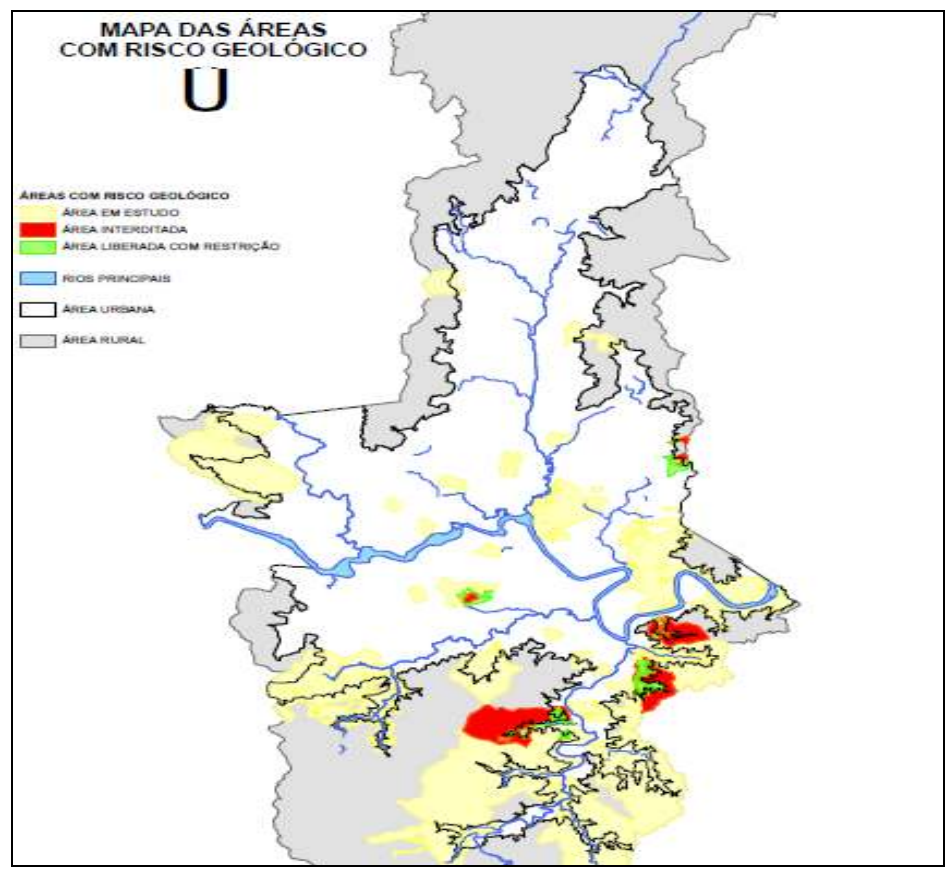

Fonte: Secretaria de Planejamento - Prefeitura de Blumenau/SC (2010) 
Conforme dados de 2009 da Secretaria de Turismo (Sectur), em 1880, na madrugada de 23 de setembro ocorreu a primeira grande enchente e o rio atingiu 14,6 metros acima do nível normal. Após 31 anos, em 2 de outubro de 1911, novamente a cidade recebeu um turbilhão de água que elevou o rio a 16,27 metros. Em julho de 1983, mais uma inundação, dessa vez com o Itajaí-Açu alcançando 15,37 metros e deixando a paisagem local parcialmente submersa durante dez dias. O desastre se repetiu em agosto de 1984, quando o nível do rio subiu para 15,67 metros.

Aquele que seria o quinto desastre de grandes proporções começou em novembro de 2008.

Após três meses de chuvas consecutivas, entre os dias 22 e 23 de novembro de 2008, Blumenau sofreu uma forte enxurrada que atingiu a região central e vários bairros. Em 48 horas, a cidade recebeu volume acumulado de chuva de quase 500 milímetros, metade dos $1.002 \mathrm{~mm}$ registrados durante todo o mês. O nível do rio Itajaí-Açu chegou a 11,52 metros acima do normal na madrugada de 23 de novembro. Com oito metros começaram a ser alagadas as primeiras ruas. O governo municipal registrou 3 mil pontos de deslizamentos de terra na cidade, 25 mil pessoas desabrigadas ou desalojadas, 24 vítimas fatais (três por afogamento e 21 por soterramento). Foram atingidas 270 ruas e interditadas 87 áreas que apresentavam movimentação do solo, dia após dia, as chuvas provocaram inundações nos vales e encharcaram o solo das encostas, que deslizaram morro abaixo com conseqüências trágicas (DIAS e MINUZZI, 2009, p. 7).

Em 22 de novembro de 2008, toda a cidade estava em situação de emergência e na noite de 23 a prefeitura decretou estado de calamidade pública. Ao sobrevoar Blumenau nesse dia, o governador de Santa Catarina, Luiz Henrique da Silva, declarou a Escandiuzzi (2008): são quase quatro meses de chuvas ininterruptas e o chão está derretendo como sorvete. Após dois dias sem chuvas, em 3 de dezembro outro temporal provocou novos deslizamentos de terra e inundou parcialmente o centro histórico da cidade.

Em 2008, o desastre provocou sérios danos paisagísticos, econômicos e sociais. De acordo com relatórios da prefeitura (2009), todas as atividades agrícolas e pecuárias foram afetadas, assim como a suinocultura e a criação de aves e peixes. Saíram prejudicadas direta ou 


\section{TURISMO EM ANÁLISE}

indiretamente as 176 atividades industriais, que reuniam 3,4 mil empresas e empregavam quase 50 mil pessoas na época da enchente. O mesmo aconteceu com o comércio e suas 153 diferentes modalidades que congregavam cerca de 9 mil estabelecimentos e 22 mil funcionários. O setor de serviços, com 117 atividades econômicas, 9,7 mil empreendimentos e 33,7 mil postos de trabalho, contabilizou enormes perdas.

Aproximadamente 103 mil pessoas, espalhadas por todo o território blumenauense, sofreram com a trágica experiência. Foi necessário o resgate de 563 moradores com helicóptero e 4,5 mil por terra, o que implicou trabalho intensivo de mais de 5 mil pessoas. Os danos materiais se acumularam com quase 2,3 mil casas destruídas. Houve corte no fornecimento de água e energia elétrica. As estações de tratamento de água e de esgoto pararam e ocorreu rompimento de adutoras e redes de distribuição. O transporte coletivo foi totalmente paralisado nos primeiros dias do desastre, por causa do alagamento e da destruição de terminais e da frota de ônibus, somados às quedas de incontáveis barreiras que impediam sua circulação nas ruas.

A saúde municipal sofreu com a destruição total ou parcial de muitos prédios públicos, o que impossibilitou o atendimento pleno da população da cidade e sua região. Com a suspensão dos serviços, mais de 8 mil atendimentos diários deixaram de ser prestados. Os danos aos prédios públicos de saúde causaram forte impacto na área de prevenção. A situação se agravou com a exposição à água e à lama contaminadas.

As atividades de educação no município foram totalmente paralisadas durante a semana do evento e, nesse período, aproximadamente 35 mil alunos não foram atendidos. A enchente danificou 61 escolas municipais e destruiu outras quatro. $O$ fornecimento de gás ficou comprometido pelo rompimento de um duto. No que se refere às obras urbanas, 1,2 mil foram danificadas e 143 destruídas.

Ironicamente, a catástrofe, uma verdadeira tragédia para a cidade, aconteceu menos de um mês após a $25^{\mathrm{a}}$ Oktoberfest (a qual compareceram 600 mil visitantes brasileiros e estrangeiros no período de 9 a 26 de outubro de 2008), que havia sido criada para resolver os problemas das enchentes de 1984. A festividade ganhou projeção internacional, consagrando-se como a segunda maior festa de tradição alemã do mundo, a maior das Américas e um dos eventos mais destacados no calendário turístico brasileiro. 
A administração municipal nos meses subsequentes à enchente ocupou espaço considerável do seu site na internet para informar e mostrar à população os efeitos da catástrofe. As imagens eram verdadeiramente chocantes, já que grande parte do cenário turístico da região estava sob as águas. Muitos locais destinados à visitação tiveram seu funcionamento comprometido, praças ficaram submersas, igrejas e edifícios antigos foram seriamente danificados e ficaram sem condições de acesso. Museus e parques foram interditados.

No entanto, mesmo com todos os danos ocorridos na infraestrutura turística os dados mostram que houve uma queda na ocupação hoteleira somente no mês de dezembro de 2008, um mês após a catástrofe (ver tabela 01).

Tabela 01 - Dados da Ocupação Hoteleira em Blumenau/SC

\begin{tabular}{|c|c|cccccc|}
\hline Ano & Janeiro & Fevereiro & Março & Outubro & Novembro & Dezembro \\
\hline 2008 & $58,36 \%$ & $53,74 \%$ & $57,52 \%$ & $74,74 \%$ & $54,92 \%$ & $36,90 \%$ \\
\hline 2009 & $54,89 \%$ & $54,76 \%$ & $57,52 \%$ & $72,41 \%$ & $52,83 \%$ & $49,25 \%$ \\
\hline
\end{tabular}

Fonte: Sindicato de Hotéis, Restaurantes, Bares e Similares de Blumenau e Região (2010)

\section{Gestão de Crise: recuperação dos destinos turísticos afetados por catástrofes}

Tsunami na Ásia, furacão nos Estados Unidos, excesso de chuvas no sul do Brasil. Em diferentes coordenadas espaciais e cronológicas, esses três fenômenos naturais provocaram catástrofes que transformaram profundamente a paisagem de importantes destinos turísticos. São exemplos de eventos geradores de crises que, segundo Dwyer e Kim (2003a), apresentam relevância para o turismo e têm impactado na escolha do destino e até mesmo na decisão de viajar. Para Dwyer (2005), a crise é qualquer evento inesperado que afeta a confiança do viajante, interfere no funcionamento normal de um destino turístico e representa ameaças não somente aos turistas, mas para todos os intervenientes do turismo. 


\section{TURISMO EM ANÁLISE}

O que se vê nos noticiários é que os desastres naturais são cada vez mais freqüentes e devastadores, com o aumento de tormentas e eventos climáticos extremos. Em 2008, como informa Chade (2009), o número de vítimas foi um dos mais altos da história: 211 milhões de pessoas afetadas no mundo. Tanto o número de mortes (236 mil) como as perdas econômicas (US\$ 181 bilhões) estiveram entre as mais altas já registradas.

As inundações aumentaram de maneira significativa em relação à média registrada entre 2000 e 2006, foram 206 desastres somente em 2007. Relatórios da ONU divulgados pelos jornais Folha de São Paulo, O Estado de S. Paulo e, O Globo em 2008, mostraram que apenas no decorrer daquele ano, 117 milhões de pessoas em todo o mundo foram vítimas de cerca de 300 desastres naturais — nos sete anos anteriores, a média foi de 170 —, incluindo secas devastadoras na China e na África e inundações na Ásia e na África, num prejuízo total de US\$ 15 bilhões. Das 197 milhões de vítimas em 2007, 164 milhões foram consequência de inundações.

No Brasil, de acordo com The International Emergency Disasters Database (EM-DAT, 2009), entre 1999 e 2008 ocorreram pelo menos 49 grandes episódios de secas, inundações e deslizamentos de terra, totalizando 5,2 milhões de pessoas atingidas, 1.168 óbitos e um prejuízo econômico de US\$ 3,5 bilhões. Dados da ONU apresentados pelo jornal O Povo (2009) revelam que no ano passado o Brasil foi o $13^{\circ}$ país mais atingido por desastres naturais, com 2 milhões de pessoas afetadas principalmente pelas chuvas.

O turismo é altamente sensível a crises e elas se agravam quando associadas a desastres e, um sistema de proteção aos turistas e de recuperação das áreas turísticas deve ser implementado pelas autoridades competentes (WTO, 1998). Como enfatizam Maditinos e Vassiliadis (2008), os desastres aumentam as preocupações de turistas com segurança e proteção colocando pressão crescente sobre planejadores e gestores envolvidos com o turismo, impelindo-os a analisar o impacto das catástrofes sobre essa indústria e a desenvolver estratégias para lidar com as crises.

A literatura sobre o gerenciamento de riscos e crises se intensificou enormemente, após o atentado de 11 de setembro de 2001 tendo se concentrado na ameaça do terrorismo (DWYER e KIM, 2003b; BLAKE e SINCLAIR, 2003). Contudo, este estudo encontra maior adequação 
às lições aprendidas com as crises posteriores do tsunami nas costas da Ásia e da África em 2004 e do furacão Katrina sobre a região de Nova Orleans em 2005. Com eles podem-se aperfeiçoar os processos de gerenciamento de crise a partir de catástrofes naturais (DWYER, 2005; RITCHIE, 2008).

Entre estes autores se destaca Dwyer (2005) por suas investigações e propostas em situações semelhantes à vivenciada por Blumenau. Seu modelo foi o que pareceu mais adequado para servir de orientação a este caso devido, principalmente a sua proposta estruturada e focada na resposta à crise e, também por que para ele, na sequência de uma crise é prioritário avaliar o papel do turismo no desenvolvimento socioeconômico da cidade ou da região.

Sendo Blumenau um município com declarada opção pelo desenvolvimento regional baseado no turismo, a abordagem de Dwyer (2005), no que compete às estratégias de gestão pós-crise foi plenamente adequada, já para ele a recuperação das áreas afetadas por catástrofes é uma função com 2 vetores inter relacionados, o social e humanitário, no que compete aos cidadãos afetados e de da recuperação da capacidade da região retomar seu desenvolvimento. Outro aspecto, importante é que a crise pode incorporar o conceito de oportunidade porque, durante o período pós-desastre, motivada por alterações contextuais e novas exigências do mercado, a indústria do turismo tende a absorver novas ideias e abordagens para estratégias futuras, ao mesmo tempo em que trabalha na reabilitação da imagem do destino.

A respeito da recuperação da área atingida, ainda Dwyer (2005) assevera que é preciso reconstruir de uma maneira responsável e sustentável, evitando-se soluções imediatistas, e comenta que isso requer atendimento a diversos aspectos do planejamento turístico, desenvolvimento de novos produtos, marketing e promoção. Ele considera que, de um modo geral, uma resposta às crises envolve cinco pilares estratégicos: restaurar infraestruturas públicas, recuperar infraestruturas públicas de apoio às atividades do setor privado, estimular a economia local, restaurar o governo e a administração civil e proteger o ambiente de novas catástrofes naturais. Outro ponto enfatizado é a necessidade de cooperação de todos os segmentos da indústria do turismo no processo de recuperação, elemento comum que aparece em todas as recuperações bem-sucedidas. Isso também se aplica ao desenvolvimento de planos de gestão de riscos com base na proposição de que "a prevenção é a melhor estratégia". 
Os envolvidos na indústria do turismo devem rapidamente restaurar a confiança no mercado de destino, com medidas honestas e éticas. Devem contextualizar o evento da crise, comunicar com exatidão a extensão e o grau do problema. Em caso de catástrofe natural, é importante que o mercado esteja consciente dos limites do desastre, dos prejuízos causados e das áreas não afetadas (DWYER, 2005).

Segundo o autor, há ainda a necessidade de uma política econômica e de assistência financeira aos diversos setores, incluindo a indústria do turismo. Os governos devem trabalhar em estreita colaboração com a indústria em momentos difíceis, oferecendo incentivos e benefícios fiscais temporários e outros subsídios para incentivar as empresas a funcionar imediatamente após uma crise. Entre eles destaca-se a disponibilização de créditos ou empréstimos que envolvam posterior reembolso.

Importante também é adotar transparência na prestação de contas relativas à gestão da ajuda recebida, em forma de dinheiro ou material doado, para atender a população afetada pela crise. É fundamental estabelecer atitude proativa e ética nas comunicações e relações com a mídia, para evitar percepções distorcidas sobre a crise e obter a cooperação dos meios de comunicação na divulgação do que está sendo feito para restaurar a normalidade. Os sites dos órgãos públicos (prefeitura e estado) são ferramentas importantes, pois a internet permite que cada destino turístico crie seu próprio canal noticioso e atualize continuamente as informações.

\section{Metodologia da Pesquisa}

A metodologia utilizada foi um estudo de caso que analisou as providências tomadas em Blumenau/SC a partir do desastre de novembro de 2008. Como já desenvolvido na seção anterior, verificou-se a adequação do modelo de resposta à crise proposto por Dwyer (2005) professor da cadeira de Travel and Tourism Economics da University of New South Wales para se proceder à investigação proposta nesse estudo.

O modelo foi sugerido a partir de uma palestra proferida pelo autor no 3rd Global Summit on Peace Through Tourism, em 2005, ainda sob o impacto dos efeitos do furacão Katrina. Dwyer 
propôs cinco pilares fundamentais para a resposta à crise que se transformou no modelo detalhado no Quadro 01.

Quadro 01 - Modelo de resposta à crise proposto por Dwyer (2005)

\begin{tabular}{|c|l|}
\hline \multicolumn{2}{|c|}{ Modelo de resposta à crise proposto por Dwyer (2005) } \\
\hline \multirow{2}{*}{$\begin{array}{c}\text { Os Cinco Pilares } \\
\text { Estratégicos do } \\
\text { modelo de } \\
\text { Dwyer(2005) }\end{array}$} & 2. Restaurar as infraestruturas públicas \\
\cline { 2 - 3 } & 3. Recuperar as infraestruturas de apoio às atividades do setor privado \\
\cline { 2 - 3 } & 4. Restaurar o governo e a administração civil \\
\cline { 2 - 3 } & 5. Proteger o ambiente de novas catástrofes naturais. \\
\cline { 2 - 3 } &
\end{tabular}

Fonte: Elaborado pelos autores

O estudo iniciou com uma pesquisa exploratória em publicações de relatos sobre a crise, seguida de entrevistas em profundidade com autoridades da administração municipal. Para Yin (2005), a utilização do estudo de caso pode ser visto como uma forma de se fazer pesquisa social empírica ao investigar-se um fenômeno atual dentro de seu contexto de vida real, onde as fronteiras entre o fenômeno e este contexto não estão claramente definidas e na situação em que múltiplas fontes de evidências são usadas. 
A coleta de dados desta pesquisa foi realizada em julho de 2009 por meio de entrevistas em profundidade a partir de um roteiro previamente estabelecido com o objetivo de resgatar cronologicamente as etapas pós-desastre e respectivas ações desenvolvidas. Todas as entrevistas foram gravadas, tendo como autoridades entrevistadas: o prefeito de Blumenau, o chefe da Defesa Civil Municipal, os secretários de Turismo, Administração Municipal, e de Gestão, e o presidente do Parque Vila Germânica (autarquia municipal responsável pela organização da Oktoberfest). Todos os entrevistados foram escolhidos por ocuparem cargos em órgãos que foram fundamentais na gestão municipal do desastre.

Para análise dos dados utilizou-se transcrições das entrevistas e outros materiais, como relatórios, artigos de jornais, sites do governo municipal e estadual, entrevistas informais, observações, para recolher uma compreensão mais detalhada do contexto. Quanto ao tratamento dos dados, as entrevistas que foram gravadas e os demais dados obtidos das outras fontes foram analisadas utilizando o software Atlas-ti. O principal documento analisado foi a Avaliação de Dados (Avadan), preparado pelo Gabinete do Prefeito sob a responsabilidade da Diretoria de Defesa Civil. Por meio desse documento, foi possível avaliar o tipo de área afetada, suas causas diretas, os danos humanos, ambientais e materiais. A administração de Blumenau pode rapidamente analisar quais as prioridades deveria atender em primeiro lugar e planejar a melhor hierarquia de intervenções, cronogramas e recursos a serem disponibilizados.

Os resultados das entrevistas com os gestores públicos e demais fontes de dados foram analisados e comparados entre si com a intenção de suprir os objetivos propostos neste estudo: delinear um cenário das ações desenvolvidas em congruência com as estratégias para resposta à crise proposta pelo modelo de Dwyer (2005), além de possibilitar o levantamento de informações que contribuam para o desenvolvimento de diretrizes e o restabelecimento do turismo na cidade de Blumenau.

\section{Resposta à Crise e Dinâmica da Reconstrução}

A análise a seguir apresentada busca verificar a compatibilidade entre as ações desenvolvidas em Blumenau a partir do desastre de novembro de 2008 e o modelo de resposta à crise de 
Dwyer (2005). Como já mencionado são cinco os pilares estratégicos previstos no modelo: restaurar as infraestruturas públicas; recuperar as infraestruturas de apoio às atividades do setor privado; estimular a economia local; restaurar o governo e a administração civil; proteger o ambiente de novas catástrofes naturais.

Reuniram-se num mesmo item as duas primeiras variáveis porque a experiência adquirida durante a pesquisa mostrou ser impraticável desvincular as infraestruturas necessárias ao funcionamento das atividades da iniciativa privada da totalidade daquelas genericamente classificadas como infraestruturas públicas.

\subsection{Restaurar as infraestruturas públicas e de apoio às atividades do setor privado}

Mediante análise dos relatórios, informações divulgadas no site da prefeitura e nas entrevistas com os gestores públicos, as primeiras ações estratégicas do governo municipal foram atender a população e recuperar as infraestruturas públicas, muitas delas fundamentais para a retomada das atividades nos diversos setores da iniciativa privada. Dia 23 de novembro, com a cidade em estado de calamidade pública, a prefeitura iniciou a limpeza e a desobstrução de ruas, calçadas, rios, ribeirões, tubulações e galerias, entre outras obras de manutenção da cidade. Até abril de 2009, já haviam sido retirados 2,6 milhões de metros cúbicos de terra, o equivalente a $65 \%$ do volume que deslizou sobre as estruturas urbanas. Todas essas informações constam dos relatórios da prefeitura de Blumenau (2009).

No auge da tragédia, mais de 5,6 mil pessoas foram conduzidas a 64 abrigos ativados pela defesa civil do município. Escolas, creches, igrejas e clubes se transformaram em alojamentos para receber os desabrigados. Para atender a essa demanda, o governo local contratou 120 educadores sociais e 15 assistentes sociais em regime temporário.

Após a fase emergencial, com a desativação dos abrigos, 316 famílias (mais de 1,4 mil pessoas) foram transferidas para sete complexos de moradias provisórias. Foi-lhes destinada parte dos donativos recebidos de várias partes do Brasil e de outros países, 5,4 mil toneladas de alimentos, 729 mil litros de água, uma tonelada de material de limpeza e higiene, além de roupas, colchões, móveis, eletrodomésticos e cobertores.

Apenas quatro dias após o início da tragédia, houve restabelecimento de $75 \%$ no fornecimento de água e de $40 \%$ no abastecimento de energia elétrica. Em menos de duas semanas, todo o 
sistema de águas e esgoto foi restabelecido. Passados três dias do evento, foi possível colocar em movimento apenas $30 \%$ do sistema de transporte coletivo urbano, mas dias depois, $98 \%$ já funcionavam normalmente. Isso permitiu a retomada de grande parte das atividades industriais e comerciais e da prestação de serviços pela iniciativa privada.

Na entrevista, o prefeito, João Paulo Kleinübing, afirmou que seria preciso entre um ano e meio e dois anos para recuperar a cidade e isso exigiria, além de recursos municipais, apoio dos governos estadual e federal. O município, pela sua própria receita, não terá condições de recompor em pouco tempo aquilo que levou anos para ser construído. Ele estimou em R \$ 215 milhões o custo da reconstrução. Somente na recuperação de sete pontes e três passarelas iniciada em maio de 2009, que foram investidos R\$ 7 milhões.

Após acelerar a compra de dez terrenos destinados a novas moradias para os desabrigados, em 10 de agosto de 2009 a prefeitura assinou o contrato de construção das primeiras 160 unidades, que fazem parte do programa Minha Casa, Minha Vida do governo federal que, por meio do qual a Caixa Econômica Federal financia empreendimentos habitacionais populares. No segundo semestre de 2010 começaram a ser entregues as primeiras unidades.

\subsection{Restaurar o governo e a administração civil}

De acordo com os relatórios divulgados pela prefeitura de Blumenau em 22 de novembro de 2008, diante da situação de emergência da cidade (o estado de calamidade foi decretado no dia seguinte), o governo municipal tratou de mobilizar todos os esforços para atendimento à população e monitoramento da crise. Elaborado o relatório de avaliação de danos, autoridades públicas e representantes de entidades civis de Blumenau se uniram para mapear o fluxo e a aplicação dos repasses emergenciais para a cidade em resposta às demandas geradas pelo impacto do desastre.

Pela internet e em contato com os meios de comunicação, o governo local adotou uma política transparente de divulgação: diariamente fornecia detalhes sobre a extensão da catástrofe, as providências para o auxílio às vítimas e como os serviços de segurança estavam trabalhando.

Em conjunto, entidades públicas e privadas analisaram os planos, projetos e programas submetidos aos governos, estadual e federal, para alcance de recursos, além de adequarem ações visando à melhor aplicação de recursos orçamentários, financeiros e técnicos. Governo 
e sociedade civil se articularam no objetivo de avaliar a evolução dos acontecimentos, seus impactos na economia local, os trabalhos de recomposição da infraestrutura e o cronograma de desembolso dos recursos federais, estaduais e de doações à Defesa Civil.

Em junho de 2009, a prefeitura publicou um relatório, descrevendo as obras desenvolvidas até então e prestando contas dos recursos destinados à ajuda humanitária e à reconstrução da cidade. O município recebeu dinheiro dos governos estadual e federal, além do suporte de entidades, como Cruz Vermelha, consulados do Japão e da Alemanha, agentes financeiros (bancos), e doações de pessoas físicas e jurídicas depositadas em conta bancária.

As autoridades locais, o setor privado e a comunidade constituíram uma aliança de trabalho e se integraram em torno do objetivo comum de recuperar a cidade, definir estratégias pós-crise e iniciar nova fase no crescimento de Blumenau. A todos os blumenauenses foram disponibilizadas informações sobre os procedimentos de aplicação, acompanhamento e avaliação de gastos e distribuição dos recursos.

Em seu site institucional, a administração municipal descreveu os passos da reconstrução, fornecendo a relação completa de obras e custos, relatando que durante os meses póscatástrofe, os trabalhos se intensificaram na recuperação de encostas, obras de drenagem e reconstrução dos sistemas de escoamento das águas pluviais. Informou o encaminhamento de sete projetos relacionados ao abastecimento de água e dois referentes ao tratamento de esgoto e resíduos sólidos. Mostrou a iniciativa de reformar e promover melhorias em escolas, creches e postos de saúde e que solicitou verba ao governo do Estado para a criação de mais vagas e ampliação de escolas para uso compartilhado entre as redes municipal e estadual.

\subsection{Estimular a economia local}

A análise dos dados obtidos por meio das diversas fontes utilizadas neste estudo revela que a política econômica de resposta à crise envolveu medidas destinadas a estimular as atividades em toda a indústria, a fim de compensar uma desaceleração, e outras direcionadas a aumentar a liquidez e impedir o fechamento de empresas. O governo municipal mobilizou empresários em torno do Programa de Apoio à Revitalização das Empresas (Revitaliza), desenvolvido com o objetivo de financiar ações voltadas para a revitalização das empresas sediadas em municípios catarinenses que decretaram situação de emergência ou calamidade pública e 
registraram perdas com as inundações. Foi lançado também um programa pelo Banco Nacional de Desenvolvimento Econômico e Social (BNDES), com apoio do Banco do Brasil, Banco Regional de Desenvolvimento do Extremo-Sul (BRDE) e Serviço Brasileiro de Apoio às Micro e Pequenas Empresas (Sebrae), que prevê liberação de crédito para as empresas que tiverem cadastro aprovado pelos agentes financeiros.

Salienta-se que, nos primeiros cinco meses de 2009, Blumenau arrecadou R\$ 562 mil a mais do que no mesmo período do ano anterior passado com o imposto sobre serviços de qualquer natureza (ISS-QN). Segundo Weiss (2009), foi um crescimento de 3\% sobre o total obtido entre janeiro e maio de 2008, mas apesar de o percentual ser pouco significativo, ganha força se forem considerados os impactos do período pós-tragédia e da crise internacional sobre a economia blumenauense.

O estímulo para o crescimento foi reflexo direto da liberação do Fundo de Garantia por Tempo de Serviço (FGTS) a todos os moradores da cidade, que potencializou o poder de compra do blumenauense em curto espaço de tempo. De acordo com dados do Sistema de Informações Gerenciais de Apoio à Decisão- SIGAD (SIGAD, 2009), a folha de pagamento dos blumenauenses é de R $\$ 120$ milhões e o FGTS liberou de uma só vez R \$ 400 milhões. Os investimentos dos consumidores na reconstrução e em serviços estimularam o aumento de circulação do capital. Um dos setores beneficiados foi o de construção civil. Novas empresas de serviço se instalaram na cidade, encorajadas pelos recursos liberados do FGTS.

Uma das principais estratégias para restauração da infraestrutura pública e de apoio às atividades do setor privado adotadas pela gestão municipal que se mostrou efetiva, após a tragédia de 2008 foi a flexibilidade do Planejamento Estratégico Municipal (PEM) para o período de 2005 a 2020, com a alocação de verbas para restaurar o ativo natural e humano da cidade, contemplando também a recuperação do turismo de lazer e eventos.

\subsection{Proteger o ambiente de novas catástrofes naturais}

Com referência à prevenção e convivência com o risco, destaca-se que, após análise documental das grandes enchentes de 1983 e 1984, Blumenau havia criado o Plano de Contingenciamento de Enchentes, que periodicamente é aperfeiçoado e são realizadas simulações para testá-lo. A política municipal de redução de riscos envolve comunicação e 


\section{TURISMO EM ANÁLISE}

intercâmbio constante de informações entre as autoridades locais e instituições de pesquisa que colaboram na manutenção de um sistema de monitoramento de fenômenos naturais e de alerta sobre riscos de desastres.

Os relatos, nas entrevistas com os gestores públicos revelam que a prefeitura estuda a criação de um código ambiental para o município, cuja proposta já consta dos trabalhos de revisão dos códigos complementares ao Plano Diretor. A Secretaria de Planejamento Urbano prevê a aprovação dos códigos complementares de circulação (que trata do trânsito municipal), parcelamento do solo, zoneamento urbano e de edificações. Todas as propostas serão apresentadas e discutidas com a comunidade em audiências públicas. Quanto às ocupações irregulares de solo, já foram mapeadas as áreas de risco e foi aumentada a fiscalização para evitar invasões.

Borba (2009), novos estudos sobre geologia, vegetação e mapeamento de área e concentração populacional irão embasar a nova legislação municipal. E devido à identificação de mais áreas com risco de desmoronamento, será preciso rever as zonas de proteção ambiental, que têm baixos índices de construção porque concentram espaços do patrimônio natural ou são áreas frágeis de encostas ou com declividade imprópria para urbanização.

A prefeitura divulgou relação de 79 áreas consideradas de risco e decretou que a remoção de entulhos e barreiras, terraplanagem, construções e reformas só podem ser executadas com autorização do governo municipal. O consentimento para a obra só é dado depois de uma análise das condições de segurança do local feita pela Defesa Civil. Também iniciou a capacitação de 900 (novecentas) pessoas que se cadastraram para atuar voluntariamente como coordenadores de abrigos.

Segundo informações da chefia de gabinete e da Diretoria de Defesa Civil, que está finalizando o novo Plano de Contingência do município, amplia de 34 para 65 os locais que servirão como abrigos e estabelece procedimentos a serem adotados em caso de desastres naturais. O plano incluirá a relação das áreas de risco em caso de deslizamentos. Cada abrigo deve ter cadastrados pelo menos 14 voluntários, treinados para cuidar de atividades como alimentação, gestão de pessoal, transporte e limpeza. 
As ações de prevenção e orientações em caso de novas calamidades ganharão reforço nas salas de aula. A partir deste segundo semestre, estudantes da $7^{\text {a }}$ série de 39 escolas municipais terão aulas e atividades extraclasse com o tema "Noções gerais de defesa civil e percepção de desastres". O projeto é uma iniciativa da Defesa Civil Estadual com o Centro de Estudos e Pesquisas sobre Desastres da Universidade Federal de Santa Catarina (UFSC). Blumenau será a primeira cidade contemplada.

$\mathrm{Na}$ sua entrevista, o prefeito de Blumenau, sr. Kleinübing, reconheceu que é preciso repensar a cidade e a forma com que vamos continuar crescendo [...] precisamos construir com consciência, onde é possível e respeitando a natureza. Ele declarou ainda que a mais importante lição tirada da tragédia é poder evitar os erros do passado. $O$ crescimento desordenado, por mais de 50 anos, nos levou a pagar o preço e temos a responsabilidade, todos, entes públicos, privados e pessoas em geral, de fazermos uma Blumenau diferente, melhor.

\section{Recuperando o Antigo Atrativo Turístico}

Nas entrevistas e nos demais dados obtidos sobre as ações planejadas pela Secretaria de Turismo para recuperar o antigo atrativo da cidade observou-se o fortalecimento de contatos com todos os agentes da cadeia turística e a execução de agressivo plano de marketing. Dentre as estratégias de comunicação, destacam-se a participação em feiras, realização de eventos itinerantes e ampla divulgação da cidade.

Apesar do cancelamento de vários eventos no período de 22 de novembro de 2008 até 07 de janeiro de 2009, incluindo eventos de grande projeção como o Salão Mundial de Artesanato, houve um grande esforço para manter a cidade como atrativo turístico, sendo refletido diretamente nas taxas de ocupação na rede hoteleira de Blumenau, havendo uma queda apenas no mês de dezembro de 2008 e tendo uma recuperação logo em janeiro de 2009 fícando dentro da média de ocupação da rede hoteleira.

Desde o final de 2008, várias estratégias vêm sendo implementadas para oferecer opções de lazer à comunidade e resgatar o fluxo turístico. O primeiro evento a ser promovido após o desastre foi a Sommerfest. Com o mesmo propósito que foi criada a Oktoberfest na primavera 
para superar as enchentes de 1983 e 1984, a Sommerfest brinda o verão e em 2009, dois meses depois de outra enchente. Com a parceria da iniciativa privada, a prefeitura promoveu a $3^{\text {a }}$. Edição da Sommerfest (Festa de verão), já consagrada no calendário de eventos de Santa Catarina nos meses de janeiro e fevereiro. A programação começou na noite de 31 de dezembro de 2008, com a Neues Jahrfest (Festa de Ano-Novo), organizada com o intuito de levantar a autoestima da população atingida em novembro pela enchente. De acordo com o presidente do Parque Vila Germânica foi a nossa festa da virada, pois viramos a página das dificuldades e começamos a escrever um novo capítulo: da superação e recuperação dos ânimos.

Integraram a Sommerfest, até 14 de fevereiro, apresentações culturais de bandas típicas e grupos folclóricos, festival gastronômico em vários restaurantes da cidade, festival de balonismo, rodas de samba e noites de mini-Oktoberfest. Nesse período, moradores e visitantes aproveitaram a promoção Liquida Blumenau (grande liquidação anual de verão no comércio local) e promoção nas tarifas dos hotéis da cidade. Em 19 de fevereiro, na Avenida Beira-Rio - um dos cartões-postais de Blumenau - aconteceu um carnaval de rua, numa manifestação da alegria dos blumenauenses compartilhada com os visitantes.

Outro evento de grande projeção nacional, realizado após as enchentes foi a Texfair 2009, a maior feira têxtil da America Latina, foi mais uma oportunidade de mostrar que a cidade já estava voltando a normalidade, tendo como público executivos de alto poder aquisitivo e formadores de opinião, assim como obtendo maior visibilidade na mídia nacional. Em fevereiro de 2009, por exemplo, a equipe de promoções da Sectur participou em São Paulo do $15^{\mathrm{o}}$ Workshop da CVC, uma das maiores operadoras de turismo do país. Segundo o presidente do Parque Vila Germânica - autarquia municipal organizadora da Oktoberfest - o objetivo foi mostrar que Blumenau está recuperada, ainda mais linda, e apresentar os atrativos turísticos da cidade que não foram afetados pela catástrofe de novembro do ano passado e divulgar a próxima Oktoberfest.

$\mathrm{Na}$ captação de fluxos turísticos, congressos, convenções e outros eventos, o governo municipal contou com o apoio do Blumenau Convention \& Visitors Bureau, que promove o marketing de destino, divulgando a cidade para ampliar o volume de turistas e de negócios. Aliada da Secretaria e do Conselho Municipal de Turismo, a entidade também ajuda a 
mobilizar as empresas do município, especialmente aquelas que pertencem ou lidam com o trade turístico, no sentido de divulgarem com mais amplitude, nos seus sites, a cidade e seus atrativos. O secretário de Turismo de Blumenau declarou em sua entrevista que os sites são excelentes ferramentas de divulgação, especialmente no momento em que todos se empenham para retomar o movimento turístico.

Outra entidade engajada nessa campanha é a Associação Empresarial de Blumenau (ACIB) e seu Núcleo de Turismo Receptivo, que propõe incluir voos panorâmicos no roteiro turístico, de forma a oferecer aos turistas a oportunidade de conhecer a cidade do alto. A ideia é bastante recente e deverá ser aprovada pelas autoridades municipais antes do contato com empresas interessadas em explorar os serviços.

O prefeito relata na sua entrevista não acreditar que a enchente resulte em prejuízos ao turismo da cidade e que as pessoas deixem de vir a Blumenau, principalmente à Oktoberfest, por conta disso. É preciso que as pessoas venham, até para nos ajudar nessa recuperação, enfatizou.

\subsection{Oktoberfest: oportunidade na crise}

"Visite a Oktoberfest de Blumenau. Apesar de tudo", dizia o cartaz usado pela rainha da primavera de Blumenau, eleita em setembro de 1984, durante suas visitas a várias cidades do país convidando para a primeira grande festa do chope no Brasil. Cabe lembrar, como coloca Duvignaud (1983), que, historicamente, um aspecto fundamental de qualquer festa é o anúncio de uma estação do ano ou de um novo tempo. Assim foi com a Oktoberfest brasileira, realizada na primavera para saudar um tempo novo, construído pela associação da perseverança, da memória e da herança cultural dos blumenauenses. De acordo com Sasse (1991), o resgate da tradição e das origens germânicas na festa foi uma tomada de consciência positiva na história de uma cidade castigada pela natureza e que sentia estar perdendo suas raízes.

Amaral (1998) conta que, para alguns, parecia impossível e absurdo que Blumenau estivesse festejando alguma coisa, mas, por solidariedade ou curiosidade, 102 mil pessoas responderam positivamente ao convite e participaram dos dez dias de festa, no período de 5 a 14 de outubro daquele ano, 60 dias depois da grande inundação de 1984. A autora comenta que se reuniram, 
sob o mesmo teto, inúmeras famílias que formaram, por sua vez, uma momentânea e monumental família, configurando um princípio comunitário de união e confraternização. Durante a primeira festa da cerveja de Blumenau, o povo bebeu, simbolicamente, toda a água do rio Itajaí-Açu, toda a herança alemã, toda a vida esquecida desde que os alemães imigrantes se instalaram em Blumenau. E brindou: Ein prosit, ein prosit der gemütlichkeit! (Um brinde, um brinde ao bem-estar!).

$\mathrm{Na}$ Oktoberfest transborda a alegria de quem a promove e de quem a visita, numa festa de hospitalidade e confraternização decorada por carros alegóricos floridos, grupos folclóricos e bandas de música alemãs, gastronomia típica e chope, tudo conjugado na construção de uma história de 26 anos, vivenciada por quase 17 milhões de festeiros.

Nos bastidores da festa movimentam-se milhares de pessoas para oferecer produtos e serviços. Tanto as que se envolvem com os preparativos quanto os visitantes se reconhecem mutuamente em sua humanidade. É uma manifestação coletiva que coloca em evidência a reapropriação ou pelo menos o desejo de recuperação de uma solidariedade, de uma vivência intensa, de um exercício de fantasia que as mutações de condições sociológicas parecem tornar cada vez mais impossíveis (CIPRIANI, 1998, p. 98).

Segundo o presidente do Parque Vila Germânica, em 2009 celebra-se 26 anos da maior festa alemã das Américas, a Oktoberfest. A cada edição, a festa vai se transformando e agrega novos elementos, ao mesmo tempo em que revitaliza tradições milenares. Estamos sempre tentando inovar, fazendo com que a Oktoberfest se solidifique ainda mais no calendário de eventos do país. Em sua 26a edição, a Oktoberfest apresenta várias novidades. Uma delas é a presença de DJs alemães, que dividem os palcos com três bandas alemãs contratadas para agitar os 18 dias de festa.

\section{Considerações Finais}

Conforme proposto no início deste trabalho, procedeu-se à análise da catástrofe que se abateu sobre Blumenau, considerando a literatura específica disponível, baseados no modelo de Dwyer (2005). Compararam-se as ações desenvolvidas no município de Blumenau para dar resposta à crise deflagrada pelo desastre de novembro de 2008, com os cinco pilares 


\section{TURISMO EM ANÁLISE}

estratégicos apresentados por esse autor: restaurar as infraestruturas públicas; recuperar as infraestruturas de apoio às atividades do setor privado; estimular a economia local; restaurar o governo e a administração civil; proteger o ambiente de novas catástrofes naturais.

O estudo demonstrou que na cidade de Blumenau as estratégias de reabilitação foram adequadas às recomendações de Dwyer (2005) para promover uma eficiente gestão da crise e de riscos. Constatou-se que desastres naturais, enfrentamento de problemas deles originados, esforços coletivos de reconstrução e direcionamento para atividades industriais e turísticas são elementos marcantes da história de Blumenau, colonizada há 150 anos por imigrantes alemães e vítima de cinco enchentes de grandes proporções, a mais recente em novembro de 2008.

Essa experiência foi importante tanto na organização do atendimento emergencial à população quanto no processo de gestão da crise deflagrada pela enchente. Num trabalho integrado e sinérgico, o governo, a iniciativa privada e a comunidade conseguiram mobilizar várias outras forças políticas e sociais em torno da recuperação da cidade.

O entendimento de que reabilitar um destino turístico e restabelecer a normalidade no cenário do desastre é providência que envolve complexas e múltiplas ações que demandam recursos econômicos, colaboração de todos os agentes sociais e tempo. Dwyer (2005) ressalta que a destruição de poucos segundos leva anos para ser reconstruída e, sem desprezar a ajuda de emergência, é de fundamental importância considerar que a reabilitação de áreas atingidas não é imediata, mas custará vários anos de esforços e sacrifícios.

Da tragédia ficou a lição de que é preciso repensar a dinâmica de desenvolvimento da cidade e reconstruí-la de maneira responsável e sustentável, num processo que inclua a paisagem, a cultura, o bem-estar e a alegria de blumenauenses e turistas. É com trabalho e confraternização que os blumenauenses se recuperam da tragédia, reagem à crise. Passados meses após a enchente e comemorando sempre com a Oktoberfest, principal atrativo turístico da cidade, nas ruas de Blumenau volta-se a ouvir mais uma vez o hino da festa: Alles gut, alles blau (Tudo bem, tudo azul). Alles himmelblau in Blumenau (Tudo está azul-celeste em Blumenau). 


\section{Referências}

ACSELRAD, H. 2002. Território e poder: a política das escalas. In: FISCHER, Tânia. Gestão do desenvolvimento e poderes locais: marcos teóricos e avaliação. Salvador: Casa da Qualidade, p. 3344.

AMARAL, R. 1998. Festa à brasileira: sentidos do festejar no país que "não é sério". Tese de Doutoramento, Universidade de São Paulo, São Paulo. Disponível em: $<$ http://www.aguaforte.com/antropologia/festabrasileira/festa.html $>$. Acesso em: 25 jul. 2009.

BLAKE, A.; SINCLAIR, M. T. 2003. Tourism Crisis Management: Responding to September 11, Annals of Tourism Research, Vol.30 (4), pp.813-832.

BORBA, J. 2009. Blumenau estuda criação de código ambiental. Clic RBS, 24 jun. Disponível em: $<$ http://www.clicrbs.com.br>. Acesso em: 25 jul. 2009.

CHADE, J. 2009. Especialista em desastres naturais da ONU critica o Brasil. O Estado de São Paulo, 22 jan. Disponível em: <http://www.estadao.com.br>. Acesso em: 23 jul. 2009.

CHOAY, F. 2001. A alegoria do patrimônio. São Paulo: Editora Unesp.

CIPRIANI, R. 1988. Experimento com histórias de vida: Itália/Brasil. Enciclopédia Aberta de Ciências Sociais. São Paulo: Vértice.

COOPER, C. et. al. 2001. Turismo, princípios e prática. 2. ed. Porto Alegre: Bookman.

DIAS, M. A. S.; MINUZZI, R. B. 2009. As chuvas de novembro de 2008 em Santa Catarina: um estudo de caso visando a melhoria do monitoramento e da previsão de eventos extremos. Florianópolis: Ciram - Centro de Informações de Recursos Ambientais e Hidrometeorologia de Santa Catarina.

DOWBOR, L. 1995. Governo e sociedade: requisitos para um projeto de desenvolvimento local. Boletim Dicas - Idéias para a ação municipal, São Paulo, Instituto Pólis, n.53. <http://www. federativo.bndes.gov.br/dicas/D053.htm>. Acesso em: 25 jul. 2009.

. 1998. Capitalismo: novas dinâmicas, outros conceitos. São Paulo em Perspectiva, São Paulo, v. 2, n. 2, abr-jun. p. 64-76.

DUVIGNAUD, J. 1983. Festas e civilizações. Rio de Janeiro, Tempo Brasileiro.

DWYER, L. 2005. Tsunamis, hurricanes, terrorism, and ???: Lessons for the global tourism industry. International Institute for Peace Through Tourism: 3rd Global Summit on Peace Through Tourism, Pattaya, Thailand, oct. 2-5. Disponível em: <http://www.iipt.org/3rdglobalsummit/.../larry\%20dwyerspeech.htm>. Acesso em: 12 jul. 2009.

.; KIM, C. 2003a. Destination competitiveness and bilateral tourism flows between Australia and Korea. The Journal of Tourism Studies, v. 14, n. 2, dec. p. 55-67.

. 2003b. Destination Competitiveness: a Model and Indicators, Current Issues in Tourism, Vol. 6, No. 5, pp 369-413.

EM-DAT. 2009. The International Emergency Disasters Database. Disponível em: $<$ http://www.emdat.be>. Acesso em: 12 jul. 2009.

ESCANDIUZZI, Fabrício. 2008. Governador de SC: chão está derretendo como sorvete. Notícias Terra, 23 nov. Disponível em: <http://www.noticias.terra.com.br>. Acesso em: 12 jul. 2009.

ESTADÃO, 2008. Desastres naturais sobrecarregam ONU e governo no Haiti, 18 set. Disponível em: $<$ http://www.estadao.com.br/.../internacional>. Acesso em: 11 jul. 2009. 
FOLHA. 2008. Desastres naturais relacionados à mudança climática aumentaram, diz ONU, 18 jan. Disponível em: <http://www.folha.uol.com.br>. Acesso em: 11 jul. 2009.

GOELDNER, C. R.; RITCHIE, J. R. B.; MCINTOSH, R. W. 2002. Turismo: princípios, práticas e filosofias. 8 ed. Porto Alegre: Bookman.

IRVING, M. A. 2002. Turismo, ética e educação ambiental. In: IRVING, M. A.; AZEVEDO, J. Turismo: o desafio da sustentabilidade. São Paulo: Futura, p. 17-34.

KRIPPENDORF, J. 2000. Sociologia do turismo: para uma nova compreensão do lazer e das viagens. São Paulo: Aleph.

LICKORISH, L. J.; JENKINS, C. L. 2000. Introdução ao turismo. Rio de Janeiro: Campus.

MADITINOS, Z.; VASSILIADIS, C. 2008. Crises and disasters in tourism industry: happen locally, affect globally. Management of International Business and Economics Systems, MIBES Conference 2008. Technological Institute of Larissa. School of Business and Economics. Larissa, Greece, 4-5 july p. 67-76.

MOESCH, M. 2000. A produção do saber turístico. 2 ed. São Paulo: Contexto.

O GLOBO. 2008. Aumentam os desastres naturais relacionados às mudanças climáticas, 18 jan. Disponível em: <http://www.oglobo.globo.com/.../2008>. Acesso em: 22 jul. 2009.

O POVO. 2009. Brasil é o $13^{\circ}$ mais afetado por desastres naturais, 23 jan. Disponível em: $<$ http://www.opovo.com.br/opovo/brasil/851232.html>. Acesso em: 22 jul. 2009.

PELLEGRINI FILHO, A. 2000. Ecologia, cultura e turismo. 5 ed. Campinas: Papirus.

PREFEITURA DE BLUMENAU. 2010. Cidade: fotos. Disponível em: $<$ http://www.blumenau.sc.gov.br/ gxpsites/hgxpp001.aspx?1,1,416,O,P,0,PAG;CONC;415;1;D;3003;1;PAG;MNU;E;3;4;MNU;,>. Acesso em 20 out. 2010.

RITCHIE, B.W. 2008. Chaos, crises and disasters: a strategic approach to crisis management in the tourism industry. International Encyclopedia of Public Health, pp. 204-215.

SASSE, M. D. 1991. Oktoberfest: a festa da cerveja. Rio de Janeiro: Ultraset.

SECTUR. 2009. Secretaria de Turismo de Blumenau. Disponível em: $<$ http://www.turismoblumenau. com.br>. Acesso em: 23 jul. 2009.

SIGAD. 2009. Sistema de Informações Gerenciais de Apoio à Decisão. Disponível em: <http://www. furb.br/ips/sigad>. Acesso em: 21 jul. 2009.

SIHORBS. 2010. Sindicato de Hotéis, Restaurantes, Bares e Similares de Blumenau e Região. Disponível em: <http://www.sihorbs.com.br/index.php>. Acesso em 10 out. 2010.

SIMÃO, M. C. R. 2001. Preservação do patrimônio em cidades. Belo Horizonte: Autêntica.

SWARBROOKE, J. 2000. Turismo sustentável: meio ambiente e economia. 2. ed. São Paulo: Aleph.

VAZ, G. N. 2001. Marketing turístico receptivo e emissivo: um roteiro estratégico para projetos mercadológicos públicos e privados. São Paulo: Pioneira.

WEISS, C. E. 2009. Arrecadação de ISS aumenta em plena crise. Folha de Blumenau, 27 jun. p. 4.

WILDE, S. J.; COX, C. 2008. Principal factors contributing to the competitiveness of tourism destinations at varying stages of development. In: S. Richardson, L. Fredline, A. Patiar \& M. Ternel (eds). Proceedings of tourism and hospitality research, training and practice: "Where the 'bloody hell' 
are we?": 18th Annual Council for Australian University Tourism and Hospitality Education, CAUTCHE Conference 2008, Surfers Paradise, Qld., 11-14 feb. 2008. Griffith University, Gold Coast, Qld. Disponível em: <http://epubs.scu.edu.au/comm_pubs/151>. Acesso em: 12 jun. 2009.

WTO. 1998. World Tourism Organization - Handbook on Natural Disaters Reduction in Tourists Areas. Madrid: Word Tourism Organization and World Meteorological Organization.

YIN, R. K. 2005. Estudo de caso: planejamento e métodos. Porto Alegre: Bookman.

Recebido em: 01/11/2009 (1 $1^{\mathrm{a}}$ versão) $12 / 11 / 2010$ ( $2^{\mathrm{a}}$ versão)

Aprovado em: 01/12/2010 